\title{
Starch digestion kinetics and mechanisms of hydrolysing enzymes in growing pigs fed processed and native cereal-based diets
}

\author{
Bianca M. J. Martens ${ }^{1,2,3}$, Thomas Flécher ${ }^{1}$, Sonja de $\operatorname{Vries}^{1}$, Henk A. Schols ${ }^{2}$, Erik M. A. M. Bruininx ${ }^{1,3}$ \\ and Walter J. J. Gerrits ${ }^{1 *}$ \\ ${ }^{1}$ Animal Nutrition Group, Wageningen University and Research, De Elst 1, 6708 WD Wageningen, The Netherlands \\ ${ }^{2}$ Laboratory of Food Chemistry, Wageningen University and Research, Bornse Weilanden 9, 6708 WG Wageningen, \\ The Netherlands \\ ${ }^{3}$ Agrifirm Innovation Center, Agrifirm Group, Landgoedlaan 20, 7325 Apeldoorn, The Netherlands \\ (Submitted 9 January 2019 - Final revision received 22 February 2019 - Accepted 24 February 2019 - First published online 06 March 2019)
}

\section{Abstract}

This study aimed to examine in vivo starch digestion kinetics and to unravel the mechanisms of starch hydrolysing enzymes. Ninety pigs (23 (sD 2.1) kg body weight) were assigned to one of nine treatments in a $3 \times 3$ factorial arrangement, with starch source (barley, maize, highamylose (HA) maize) and form (isolated, within cereal matrix, extruded) as factors. We determined starch digestion coefficients (DC), starch breakdown products and digesta retention times in four small-intestinal segments (SI1-4). Starch digestion in SI2 of pigs fed barley and maize, exceeded starch digestion of pigs fed HA maize by $0.20-0.33$ DC units $(P<0 \cdot 01)$. In SI3-4, barley starch were completely digested, whereas the cereal matrix of maize hampered digestion and generated $16 \%$ resistant starch in the small intestine $(P<0 \cdot 001)$. Extrusion increased the DC of maize and HA maize starch throughout the small intestine but not that of barley $(P<0.05)$. Up to $25 \%$ of starch residuals in the proximal small intestine of pigs was present as glucose and soluble $\alpha(1-4)$ maltodextrins. The high abundance of glucose, maltose and maltotriose in the proximal small intestine indicates activity of brush-border enzymes in the intestinal lumen, which is exceeded by $\alpha$-amylase activity. Furthermore, we found that in vivo starch digestion exceeded our in vitro predictions for rapidly digested starch, which indicates that the role of the stomach on starch digestion is currently underestimated. Consequently, in vivo glucose release of slowly digestible starch is less gradual than expected, which challenges the prediction quality of the in vitro assay.

\section{Key words: Cereals: Extrusion: In vitro: In vivo: Maltodextrins}

Starch is the main energy source in common pig diets. Starch in pig diets originate from various botanic origins, causing variation in digestion rate in the gastro-intestinal tract (GIT) and thus in glucose appearance kinetics in the portal circulation ${ }^{(1)}$. Variation in starch digestion kinetics has been demonstrated to affect pig performance. For example, pigs fed diets containing high amounts of non-digestible starch (resistant starch, RS) or slowly digestible starch (SDS) had longer meal durations and inter-meal intervals ${ }^{(2)}$ and lower energy losses by activity-related heat production $^{(3)}$, when compared with pigs fed rapidly digestible starch (RDS). Also, asynchrony between the rates of glucose and amino acid appearance in the blood negatively affects protein utilisation in restrictively fed pigs ${ }^{(4)}$ and poultry ${ }^{(5)}$. In addition, variation in the presence of starch in the ileum and colon can influence the degradation of other macronutrients, notably recalcitrant fibres ${ }^{(6)}$.
Starch is composed of two types of polysaccharides: amylose, a linear $\alpha(1-4)$ linked glucan, and the much larger amylopectin, an $\alpha(1-4)$ linked glucan that contains around 5\% $\alpha(1-6)$ linkages, resulting in a branched molecule ${ }^{(7)}$. These two polysaccharides both form three-dimensional double helices that are packed in either dense A-type crystals or less dense B-type crystals $^{(7)}$. These crystalline regions form shells that ultimately result in water-insoluble granules, which highly vary in size, shape and porosity ${ }^{(8,9)}$. In vitro studies showed that these intrinsic properties of starch cause variation in starch digestion kinetics. Although many of the structural and molecular properties of starch are inter-related within a botanic source of starch, B-type crystalline structure and long amylopectin side chains generally reduce digestion rate across botanic sources $^{(1,10,11)}$. Within starch of cereal origin, the number of pores

Abbreviations: BW, body weight; DC, digestion coefficient; DP, degree of polymerisation; EB, barley starch in extruded form; GA, high-amylose maize starch in ground form; GB, barley starch in ground form; GIT, gastrointestinal tract; GM, maize starch in ground form; HA, high-amylose; IA, high-amylose maize starch in isolated form; IB, barley starch in isolated form; IM, maize starch in isolated form; MRT, mean retention time; RDS, rapidly digestible starch; RS, resistant starch; SDS, slowly digestible starch; SEM, scanning electron microscope; SI, small intestine. 
and the amylopectin:amylose ratio are positively correlated with in vitro digestion rate ${ }^{(9,11)}$. Several in vivo studies confirm these in vitro findings, as starch with a high-amylose (HA) content and B-type crystalline structure positively correlate with lower incremental plasma glucose concentrations in pigs ${ }^{(1,12)}$. Apart from intrinsic starch properties, the extrinsic cereal matrix affects digestibility. Most cereals fed to pigs are known to have two types of endosperm tissue in which starch is stored: in soft endosperm starch granules are loosely organised within the cell, whereas in hard endosperm starch is densely packed within cell walls and proteins, decreasing the degradability of endosperm tissue ${ }^{(13,14)}$. In addition, digestibility of the cereal endosperm tissue is affected by the cell wall architecture. Plant cell walls are degraded for approximately $20 \%$ when leaving the ileum of monogastrics, but the extent depends greatly on the molecular structure and composition of the cell wall ${ }^{(15)}$. Feed processing can increase starch digestion by reducing the particle size of the cereal matrix, thereby partly disrupting the cell wall matrix and by (partly) gelatinising the starch, for example, in pelleted ${ }^{(16,17)}$ or extruded diets ${ }^{(17)}$.

Although in vitro starch digestion kinetics have been studied extensively, in vivo evidence is scarce and typically focuses on ileal starch disappearance ${ }^{(17,18)}$ or glucose appearance in the portal vein ${ }^{(19)}$ or peripheral plasma ${ }^{(12)}$. Knowledge on starch breakdown mechanisms inside the GIT is largely based on in vitro studies, with a rather unknown contribution of brushborder enzymes or digesta passage kinetics. Furthermore, studies on the interaction between cereal matrix, processing and starch source towards digestion kinetics are scarce, complicating the prediction of starch digestion kinetics in a complete diet. The aim of the present study was to assess the effects of botanic source (barley, maize, HA maize) and starch form (isolated, in the cereal matrix or extruded) on the kinetics of starch disappearance along the GIT of pigs. In addition, we compared the in vivo outcome with an in vitro method, as described by Englyst et al. ${ }^{(20)}$, on starch digestion kinetics of those nine diets. The concentration and structure of unabsorbed starch residuals in digesta were measured to increase insight into the mechanisms of starch digesting enzymes. We hypothesised that extrusion would increase the rate of in vivo starch digestion and that an increase in amylose content would decrease the rate of digestion.

\section{Methods}

The experiment was conducted at research farm 'Laverdonk' of Agrifirm Innovation Center (Heeswijk-Dinther, the Netherlands). All experimental procedures were approved by the Dutch Central Committee of Animal Experiments (the Netherlands) under the authorisation number AVD260002016550.

\section{Animals, housing and experimental design}

Ninety crossbred gilts (Topigs 20× Pietrain sire), weighing $23 \cdot 1 \pm 2 \cdot 1 \mathrm{~kg}$, were assigned to one of nine treatment combinations in a $3 \times 3$ factorial arrangement, in four successive batches of maximum twenty-four pigs each. Factors were starch source (barley $v$. maize $v$. HA maize) and form (as isolated starch $v$. ground cereal $v$. extruded cereal). The resulting dietary treatments were abbreviated as follows: barley starch in isolated (IB), ground (GB) and extruded (EB) forms; maize starch in isolated (IM), ground (GM) and extruded (EM) forms; and HA maize starch in isolated (IA), ground (GA) and extruded (EA) forms.

In total, ninety-six pigs were used: ten pigs were assigned per treatment, whereas the remaining animals served as reserve animals and were used to replace excluded animals. Seven pigs had to be excluded from the study because of feed refusals exceeding $20 \%$ of their feed allowance during the $24 \mathrm{~h}$ before dissection. Another seven pigs were excluded due to a prolonged reduction in feed intake ( $>4 \mathrm{~d}$ ) and signs of an Escherichia coli infection during the experimental period. Pigs that were excluded in one of the first three batches were replaced in the sequential batch. Replacement was done in such a way that a minimum of seven observations was realised for each dietary treatment.

The experiment consisted of an adaptation period of at least $2 \mathrm{~d}$, during which the animals were gradually switched from a commercial grower diet (Agrifirm Feed) to the experimental diets, followed by an experimental period of at least $12 \mathrm{~d}$, during which the experimental diets were fed. Pigs were housed in groups of four animals per pen $\left(0.91 \mathrm{~m}^{2}\right.$ per animal; 6:1 ratio of solid to slatted floor). To enable individual feeding, animals were separated using physical barriers through which they could still see, hear, smell and touch each other. The animals remained individually housed for the duration of feeding (max $1 \mathrm{~h}$ per meal, two meals per $\mathrm{d}$ ), after which they were group-housed again. Pigs always had free access to water, and pens were enriched with a toy that was changed regularly (every $2-3 \mathrm{~d}$ ). Temperature in the barn was maintained at $25 \pm 1^{\circ} \mathrm{C}$. Lights were on from 06.00 to 19.00 hours, except for the $2 \mathrm{~d}$ before dissection (lights on from 06.00 to 22.00 hours), and the night before dissection (lights on from 02.30 hours onwards). Animals were fed $2 \cdot 0 \times$ the energy requirements for maintenance $(750 \mathrm{~kJ}$ net energy $/ \mathrm{kg}$ body weight $\left.(\mathrm{BW})^{0.60}\right)^{(21)}$, divided over two equal meals at 08.00 and 16.00 hours. Diets were fed as mash and mixed with water just before feeding. In the first batch, a feed:water ratio of 1:2 was applied. After the first batch, the feed:water ratio of the ground diets was altered to $1: 1.5$ to facilitate ingestion, whereas the feed: water ratio was maintained at 1:2 for other treatments. During the last $2 \mathrm{~d}$ of the experimental period, the daily allowance of the pigs was equally divided over six meals, starting at 07.00 and applying a between-meal interval of $3 \mathrm{~h}$, to reach a constant passage rate of digesta through the GIT. Just before dissection, a frequent feeding procedure was applied to enable the measurement of digesta passage kinetics: each pig was fed six meals containing $1 / 12$ th of their daily allowance each, applying a $1 \mathrm{~h}$ between-meal interval. The first of the six hourly meals was fed exactly $6 \mathrm{~h}$ before a pig was euthanised. Pigs were euthanised and dissected in an order balanced for treatment and time after onset of the frequent feeding procedure. Upon the start of the frequent feeding procedure of the first pig, extra meals (1/12th of daily feed allowance) were provided with 2 -h intervals to the pigs whose frequent feeding procedure had not yet 
started, to prevent restlessness in the barns. Pigs were weighed when they entered the barns, $7 \mathrm{~d}$ before dissection and on the day of dissection.

\section{Diets and processing}

Nine diets, containing approximately $400 \mathrm{~g}$ of starch/kg DM, were formulated to meet or exceed the nutrient requirements of growing pigs ${ }^{(21)}$ (Table 1). Barley grain and purified starch, isolated from the same barley grains, were obtained from Altia Corporation. Maize and HA maize and purified starch, again isolated from the same maize grains, were obtained from Roquette. Whole grains were ground by a hammer mill $(3 \mathrm{~mm}$ sieve) and used as such, or extruded and subsequently reground by a hammer mill $(3 \mathrm{~mm}$ sieve). Diets with isolated starch were formulated to be identical in crude protein, fat and total dietary fibre content to diets including native or extruded grains, using soyabean meal, hulls, protein isolate, oil and sugar beet pulp. Cr and Co were included as markers in the feed at a level of $170 \mathrm{mg} / \mathrm{kg}$ (w/w, as-fed basis), in the form of chromium oxide $\left(\mathrm{Cr}_{2} \mathrm{O}_{3}\right)$ and Co-EDTA, respectively.

Extrusion was performed in a co-rotating twin-screw extruder (M.P.F.50; Baker Perkins) as described by de Vries et $a l^{(22)}$. Briefly, the extruder consisted of nine heating zones and a die with two orifices $(\varnothing 3.8 \mathrm{~mm})$. Temperatures in the nine heating zones were set at $30,40,50,60,70,80,95,105$ and $110^{\circ} \mathrm{C}$, respectively. The actual values of all heating zones were close to the set values, except the one to last zone, which was set at

Table 1. Ingredient and nutrient composition of diets containing barley, maize or high-amylose maize starch included as isolated powder, ground cereal or extruded cereal $^{\star}$

Inclusion level (as-is basis)

\begin{tabular}{|c|c|c|c|c|c|c|c|c|}
\hline IB & GB & EB & IC & GC & EC & IA & GA & EA \\
\hline \multicolumn{9}{|l|}{441.0} \\
\hline & 800.0 & & & & & & & \\
\hline & & 800.0 & & & & & & \\
\hline & & & 441.0 & & & & & \\
\hline & & & & 668.9 & & & & \\
\hline & & & & & 668.9 & & & \\
\hline & & & & & & 441.0 & & \\
\hline & & & & & & \multicolumn{3}{|c|}{$745 \cdot 3$} \\
\hline & & & & & & & & $745 \cdot 3$ \\
\hline $110 \cdot 0$ & & & $110 \cdot 0$ & & & 110.0 & & \\
\hline 50.8 & & & 50.8 & & & 50.8 & & \\
\hline 200.0 & & & 200.0 & 109.0 & 109.0 & 200.0 & $56 \cdot 7$ & $56 \cdot 7$ \\
\hline 92.0 & 105.1 & 105.1 & 92.0 & 132.7 & $132 \cdot 7$ & 92.0 & 109.6 & 109.6 \\
\hline 54.8 & 36.9 & 36.9 & 54.8 & 30.7 & 30.7 & 54.8 & $21 \cdot 6$ & 21.6 \\
\hline 27.4 & $22 \cdot 3$ & $22 \cdot 3$ & 27.4 & 27.6 & 27.6 & $27 \cdot 4$ & 27.9 & 27.9 \\
\hline 5.0 & 5.0 & 5.0 & 5.0 & 5.0 & $5 \cdot 0$ & 5.0 & 5.0 & 5.0 \\
\hline 3.0 & 3.0 & 3.0 & 3.0 & 3.0 & 3.0 & 3.0 & 3.0 & 3.0 \\
\hline 4.6 & $5 \cdot 7$ & 5.7 & 4.6 & 5.0 & 5.0 & 4.6 & $7 \cdot 3$ & 7.3 \\
\hline 4.0 & 4.9 & 4.9 & 4.0 & 4.2 & 4.2 & 4.0 & $5 \cdot 2$ & $5 \cdot 2$ \\
\hline 2.8 & 8.0 & 8.0 & 2.8 & 8.4 & 8.4 & 2.8 & $9 \cdot 8$ & $9 \cdot 8$ \\
\hline 2.9 & 1.5 & 1.5 & 2.9 & 1.5 & 1.5 & 2.9 & $2 \cdot 2$ & 2.2 \\
\hline 1.5 & 1.1 & 1.1 & 1.5 & 0.8 & 0.8 & 1.5 & 1.8 & 1.8 \\
\hline 0.3 & 6.5 & 6.5 & 0.3 & 3.3 & 3.3 & 0.3 & 4.4 & 4.4 \\
\hline & & & & & & & 0.3 & 0.3 \\
\hline $170 \cdot 0$ & $170 \cdot 0$ & $170 \cdot 0$ & $170 \cdot 0$ & 170.0 & $170 \cdot 0$ & $170 \cdot 0$ & $170 \cdot 0$ & $170 \cdot 0$ \\
\hline $170 \cdot 0$ & 170.0 & 170.0 & 170.0 & 170.0 & $170 \cdot 0$ & 170.0 & $170 \cdot 0$ & $170 \cdot c$ \\
\hline 423 & 444 & 470 & 423 & 472 & 482 & 401 & 467 & 474 \\
\hline 20 & 20 & 20 & 20 & 20 & 20 & 55 & 55 & 55 \\
\hline 189 & 190 & 192 & 191 & 200 & 189 & 194 & 199 & 192 \\
\hline 66 & 56 & 48 & 65 & 64 & 45 & 66 & 60 & 42 \\
\hline 63 & 64 & 63 & 65 & 65 & 62 & 64 & 64 & 62 \\
\hline 102 & 105 & 59 & 105 & 111 & 65 & 107 & 114 & 67 \\
\hline 10.5 & 10.1 & 10.1 & 10.5 & 10.2 & $10 \cdot 2$ & 10.5 & $10 \cdot 6$ & $10 \cdot 6$ \\
\hline $7 \cdot 2$ & 8.2 & 8.2 & $7 \cdot 2$ & 8.5 & 8.5 & $7 \cdot 2$ & 8.5 & 8.5 \\
\hline $10 \cdot 8$ & 10.8 & 10.8 & 10.8 & 10.8 & 10.8 & 10.8 & $10 \cdot 8$ & 10.8 \\
\hline 5.8 & 5.8 & 5.8 & 5.8 & 5.8 & $5 \cdot 8$ & 5.8 & $5 \cdot 8$ & $5 \cdot 8$ \\
\hline 6.0 & 6.0 & 6.0 & 6.0 & 6.0 & 6.0 & 6.0 & $6 \cdot 0$ & 6.0 \\
\hline 2.0 & $2 \cdot 2$ & $2 \cdot 2$ & 2.0 & $2 \cdot 1$ & $2 \cdot 1$ & 2.0 & $2 \cdot 0$ & 2.0 \\
\hline
\end{tabular}

Barley starch $\dagger(\mathrm{g} / \mathrm{kg})$

Ground barley† $(\mathrm{g} / \mathrm{kg})$

Extruded barley† ( $\mathrm{g} / \mathrm{kg})$

Maize starch $\ddagger(\mathrm{g} / \mathrm{kg})$

Ground maize $\ddagger(\mathrm{g} / \mathrm{kg})$

Extruded maize $\ddagger(\mathrm{g} / \mathrm{kg})$

High-amylose maize starch $\ddagger(\mathrm{g} / \mathrm{kg})$

Ground high-amylose maizeł $(\mathrm{g} / \mathrm{kg})$

Extruded high-amylose maize $\ddagger$ (g/kg)

Soyabean meal $(\mathrm{g} / \mathrm{kg})$

Sugar beet pulp $(\mathrm{g} / \mathrm{kg})$

Soyabean hulls $(\mathrm{g} / \mathrm{kg})$

Soyabean protein isolate§ $(\mathrm{g} / \mathrm{kg})$

Soya oil $(\mathrm{g} / \mathrm{kg})$

Dicalcium phosphate $(\mathrm{g} / \mathrm{kg})$

Mineral and vitamin premix\| $(\mathrm{g} / \mathrm{kg})$

Salt $(\mathrm{NaCl})(\mathrm{g} / \mathrm{kg})$

L-Lys $\mathrm{HCl}(\mathrm{g} / \mathrm{kg})$

$\mathrm{NaHCO}_{3}(\mathrm{~g} / \mathrm{kg})$

$\mathrm{KHCO}_{3}(\mathrm{~g} / \mathrm{kg})$

DL-Met $(\mathrm{g} / \mathrm{kg})$

L-Thr $(\mathrm{g} / \mathrm{kg})$

$\mathrm{CaCO}_{3}(\mathrm{~g} / \mathrm{kg})$

L-Trp $(\mathrm{g} / \mathrm{kg})$

$\mathrm{Cr}_{2} \mathrm{O}_{3}(\mathrm{mg} / \mathrm{kg})$

Co-EDTA (mg/kg)

Analysed nutrient composition (DM basis)

Starch $(\mathrm{g} / \mathrm{kg})$

Amylose (as percentage of starch)

Protein $(\mathrm{g} / \mathrm{kg})$

Fat $(\mathrm{g} / \mathrm{kg})$

Ash $(\mathrm{g} / \mathrm{kg})$

Moisture ( $\mathrm{g} / \mathrm{kg}$ as is)

Energy and apparent ileal digestibility levels of $\mathrm{P}$ and amino acids $\uparrow$

Net energy (MJ/kg DM)

$\mathrm{P}(\mathrm{g} / \mathrm{kg} \mathrm{DM})$

Lys ( $g /$ net energy)

Met + cysteine ( $\mathrm{g} /$ net energy)

$\operatorname{Thr}(\mathrm{g} / \mathrm{net}$ energy)

$\operatorname{Trp}(\mathrm{g} / \mathrm{net}$ energy)

$441 \cdot 0$

* Diets are abbreviated as follows: barley starch in isolated (IB), ground (GB), and extruded (EB) forms; maize starch in isolated (IM), ground (GM) and extruded (EM) forms; and high-amylose maize starch in isolated (IA), ground (GA) and extruded (EA) forms.

† Altia Corporation, Koskenkorva.

$\ddagger$ Roquette, Lestern, France.

§ Unisol NRG IP Non-GMO, Vitablend, Wolvega, The Netherlands.

II Provided per $\mathrm{kg}$ of diet: vitamin A (retinyl acetate), $10000 \mathrm{IU}$ (3000 $\mu \mathrm{g}$ retinol activity equivalents); vitamin $\mathrm{D}_{3}$ (cholecalciferol), $2000 \mathrm{IU}$ (50 $\mu \mathrm{g}$ vitamin $\mathrm{D}_{3}$ ); vitamin $\mathrm{E}$ (DL-a-tocopherol), $40 \mathrm{mg}$; vitamin $\mathrm{K}_{3}$ (menadione), $1.5 \mathrm{mg}$; vitamin $\mathrm{B}_{1}$ (thiamin), $1.0 \mathrm{mg}$; vitamin $\mathrm{B}_{2}$ (riboflavin), $3 \mathrm{mg} ;$ vitamin $\mathrm{B}_{6}$ (pyridoxine- $\mathrm{HCl}$ ), $1.5 \mathrm{mg} ;$ vitamin $\mathrm{B}_{12}$ (cyanocobalamin), $20 \mu \mathrm{g}$; niacin, $30 \mathrm{mg}$; D-pantothenic acid, $15 \mathrm{mg}$; choline chloride, $150 \mathrm{mg}$; folic acid, $0.4 \mathrm{mg}$; biotin, $0.05 \mathrm{mg}$; Fe, $100 \mathrm{mg}$, as FeSO $\mathrm{H}_{2} \mathrm{O}$; $\mathrm{Cu}, 20 \mathrm{mg}$, as $\mathrm{CuSO}_{4} \cdot 5 \mathrm{H}_{2} \mathrm{O} ; \mathrm{Mn}, 30 \mathrm{mg}$, as $\mathrm{MnO} ; \mathrm{Zn}, 70 \mathrm{mg}$, as $\mathrm{ZnSO}_{4} \cdot \mathrm{H}_{2} \mathrm{O}$; I, $1 \mathrm{mg}$, as $\mathrm{KI}$; Se, $0.25 \mathrm{mg}$, as $\mathrm{Na}_{2} \mathrm{SeO}_{3}$.

I Calculated based on data from Centraal Veevoeder Bureau ${ }^{(21)}$. 
$105^{\circ} \mathrm{C}$ but reached a temperature of maximum $145^{\circ} \mathrm{C}$. The speed of the extruder screw was fixed at $160 \mathrm{rpm}$ and the measured product temperatures at the die ranged from 97 to $99^{\circ} \mathrm{C}$ for barley, 95 to $96^{\circ} \mathrm{C}$ for maize and 95 to $97^{\circ} \mathrm{C}$ for $\mathrm{HA}$ maize diets. Water was added to the ground cereal directly in the extruder with a water pump at 6.8 litres/h, and the measured product throughput was $55 \mathrm{~kg}$ dry cereals/h. The extruded cereals were subsequently air-dried at $55^{\circ} \mathrm{C}$ overnight in air-forced ovens.

\section{Digesta collection}

Before dissection, pigs were sedated by intramuscular injection of a mixture of xylazine ( $2 \mathrm{mg} / \mathrm{kg} \mathrm{BW})$ and zolitil $(4 \mathrm{mg} / \mathrm{kg}$ BW). After sedation, pigs were injected intravascular with pentobarbital ( $24 \mathrm{mg} / \mathrm{kg} \mathrm{BW}$ ) and exsanguinated. Immediately after exsanguination, clamps were placed between the stomach and small intestine (SI) and between the SI and caecum, to prevent the movement of digesta, and the organs were carefully removed. The SI was spread on a table and divided with clamps in four segments. The terminal $1.5 \mathrm{~m}$ from the SI (SI4) was considered to represent the ileum. The rest of the SI was divided into three parts of equal length (SI1, SI2 and SI3, from proximal to distal SI, respectively). All parts were dissected and their contents were collected by gently stripping. The total weight of the digesta was recorded and a representative sample was immediately frozen on dry-ice and kept at $-20^{\circ} \mathrm{C}$ until freeze-drying. After freeze-drying, samples were ground to pass a $1 \mathrm{~mm}$ sieve using a centrifugal mill at 12000 rpm (ZM200; Retsch).

\section{Chemical analyses}

Before chemical analysis, feed samples were ground in the same way as digesta samples. All analyses were performed in triplicate, unless indicated otherwise. DM content of digesta was determined in singlicate by recording the weight before and after freeze-drying. DM content in feed was determined in duplicate according to NEN-ISO $6496^{(23)}$. Total starch content of all diet and digesta samples was determined according to AOAC method 996.11 with the total starch assay kit from Megazyme. In short, digesta and feed samples were dissolved in $\mathrm{KOH}$ (kit procedure c) followed by enzymatic hydrolysis of the starch (kit procedure a). The glucose concentration was determined with hexokinase-glucose-6phosphate dehydrogenase reagent (Roche). Samples were not washed with water or ethanol before analysis, thus the total starch content as measured in this study includes free glucose and soluble maltodextrins. Amylose content of starch was determined in isolated starch, according to the amylose/ amylopectin procedure of Megazyme (K-AMYL 06/18). N content of the diets was determined in duplicate according to NEN-EN-ISO 5983-2 ${ }^{(23)}$. Crude fat of the diets was determined in duplicate according to NEN-ISO $6492^{(23)}$. Ash content of the diets was determined in duplicate according to NEN-ISO $5984^{(23)}$. The total dietary fibre content of the diets was calculated as total DM minus crude fat, $\mathrm{N}$, ash and $\operatorname{starch}^{(21)}$. Concentrations of $\mathrm{Cr}$ and $\mathrm{Co}$ were determined in singlicate in digesta and feed material by inductively coupled plasma optical emission spectroscopy. Cr and Co were measured at a wavelength of 357.9 and $228.0 \mathrm{~nm}$, respectively, as described by van Bussel et al. ${ }^{(24)}$, after sample preparation according to Williams et al. ${ }^{(25)}$

The structure of unabsorbed starch residuals in the small intestine of pigs was analysed using a scanning electron microscope (SEM). From each treatment, one pig was selected that had digesta mean retention times (MRT) and starch digestion coefficients (DC), in all small-intestinal compartments, which were close to the average MRT and DC within that treatment. Only digesta that had more than $10 \%$ unabsorbed starch residuals (DC >0.9) could be analysed with SEM. Feed samples and fresh digesta, directly frozen after collection, were washed subsequently with hexane, twice with demi water and finally with $96 \%$ ethanol. All washing steps were performed at room temperature, with an approximate ratio of digesta to solvent of 1:4. In between each washing step, the sample was centrifuged for $10 \mathrm{~min}$ at $2000 \mathrm{~g}$, before the solvent was discarded. Samples were dried for $48 \mathrm{~h}$ at $40^{\circ} \mathrm{C}$ in an oven. Dried digesta were attached on SEM sample holders using carbon adhesive tabs (EMS) and sputter coated with $15 \mathrm{~nm}$ tungsten (EM SCD 500; Leica). Starch granules and granular residues were analysed with a field emission SEM (Magellan 400; FEI) with secondary electron detection at $2 \mathrm{kV}$. When digesta consisted of large pieces (e.g. digesta of pigs fed ground cereals), those pieces were attached on SEM sample holders using carbon adhesive tabs in combination with carbon adhesive (EMS). The samples were sputter coated twice, in opposite positions at angles of $45^{\circ}$, with $15 \mathrm{~nm}$ tungsten.

Glucose and starch-derived maltodextrins in the watersoluble fractions of feed and digesta were analysed with a high-performance anion exchange chromatography system with pulsed amperometric detection (HPAEC-PAD). Digesta samples were pooled by intestinal segment and pig within treatment, based on weight. Diet and pooled digesta samples were boiled for $5 \mathrm{~min}(50 \mathrm{mg} / \mathrm{ml})$ before centrifugation. Supernatant was diluted and analysed on a ICS5000 HPAEC-PAD (Dionex Corporation) equipped with a CarboPac PA-1 column (inner diameter $2 \mathrm{~mm} \times 250 \mathrm{~mm}$ ) and a CarboPac PA guard column (inner diameter $2 \mathrm{~mm} \times 25 \mathrm{~mm}$ ). The flow rate was set at $0.3 \mathrm{ml} / \mathrm{min}$. The two mobile phases were (A) $0.1 \mathrm{~m} \mathrm{NaOH}$ and (B) $1 \mathrm{~m} \mathrm{NaOAc}$ in $0 \cdot 1 \mathrm{~m} \mathrm{NaOH}$ and the column temperature was $20^{\circ} \mathrm{C}$. The elution profile was as follows: $0-37 \mathrm{~min}, 5-30 \cdot 9 \% \mathrm{~B}$; $37-50 \mathrm{~min}, 30 \cdot 9-100 \% \mathrm{~B} ; 50-55 \mathrm{~min}, 100 \% \mathrm{~B} ; 55-55.1 \mathrm{~min}$, $100-5 \% \mathrm{~B}$; and finally column re-equilibration by $5 \% \mathrm{~B}$ from 55.1 to $65 \mathrm{~min}$. The injection volume was $10 \mu \mathrm{l}$. Calibration curves of glucose, maltose, maltotriose, maltotetraose, maltopentaose and maltohexose were used to quantify the concentration of glucose and linear $\alpha(1-4)$ maltodextrins with degree of polymerisation (DP) 1, 2, 3, 4, 5 and 6, respectively. Furthermore, maltohexose was used to quantify concentrations of maltodextrins with DP $>6$.

In vitro starch digestion kinetics were evaluated using a digestion method described by Englyst et al. ${ }^{(20)}$ and van Kempen et $a{ }^{(19)}$. Briefly, $500 \mathrm{mg}$ of starch was incubated with pepsin (P-7000) in a hydrochloric acid solution $(0.05 \mathrm{~mol} / \mathrm{l})$, containing guar-gum and $50 \%$ saturated benzoic acid at $\mathrm{pH} 3$ 
and $39^{\circ} \mathrm{C}$ for $30 \mathrm{~min}$. Following, the $\mathrm{pH}$ was changed to 6 by adding a sodium acetate buffer $(0.5 \mathrm{~mol} / \mathrm{l})$ containing porcine pancreatin (P-7545), amyloglucosidase (A7095) and invertase (I4504), and the sample was incubated at $39^{\circ} \mathrm{C}$ for $360 \mathrm{~min}$. In contrast to the assay described by van Kempen et al. ${ }^{(19)}$, samples were incubated in a head-over-tail mixing device ( $8 \mathrm{rpm}$ ) located in an oven. Furthermore, glucose concentrations were measured in smaller aliquots in a ninety-six wells plate using a glucose oxidase peroxidase assay (Megazyme).

\section{Calculations and statistical analyses}

In vivo DC of starch were calculated based on the dual-marker method with two indigestible markers for the insoluble $\left(\mathrm{Cr}_{2} \mathrm{O}_{3}\right)$ and soluble (CO-EDTA) digesta fractions and starch concentrations in feed and digesta (equation 1$)^{(26)}$. Because starch is partly solubilised during digestion, undigested starch behaves partly as insoluble and partly as a soluble compound, which differed significantly in passage behaviour throughout the SI (BMJ Martens, M Noorloos, S de Vries, HA Schols, EMAM Bruininx and WJJ Gerrits, unpublished results). The fraction of starch found as glucose and soluble oligomers and polymers was used to calculate DC, according to equation 1.

$$
\operatorname{DC}(n)=1-\left(\frac{\left[\mathrm{Cr}_{\mathrm{F}}\right] \times(1-S)\left[\operatorname{starch}_{\mathrm{D}}\right]}{\left[\mathrm{Cr}_{\mathrm{D}}\right] \times\left[\text { starch }_{\mathrm{F}}\right]}+\frac{\left[\mathrm{CO}_{\mathrm{F}}\right] \times(S)\left[\operatorname{starch}_{\mathrm{D}}\right]}{\left[\mathrm{Co}_{\mathrm{D}}\right] \times\left[\text { starch }_{\mathrm{F}}\right]}\right)
$$

where $\operatorname{DC}(n)$ is the digestibility coefficient of starch in the compartment $n$ as fraction of ingested starch, [Co] is the concentration of soluble indigestible marker dosed in feed (F) or measured in digesta (D) (mg/g DM), $[\mathrm{Cr}]$ is the concentration of insoluble indigestible marker dosed in feed (F) or measured in digesta (D) ( $\mathrm{mg} / \mathrm{g} \mathrm{DM})$, [starch] is the concentration of starch measured in feed (F) or digesta (D) $(\mathrm{mg} / \mathrm{g}$ DM), $S$ represents glucose and soluble starch-derived maltodextrins, as fraction of the total amount of starch in digesta. In addition, DC were calculated with $\mathrm{Cr}_{2} \mathrm{O}_{3}$ as the only marker (referred to as $\mathrm{DC}_{\mathrm{cr}}$ ), according to the commonly used single-marker method ${ }^{(27)}$.

To study starch digestion kinetics, the DC was plotted against the cumulative retention time (CRT) of starch per segment $(n)$ of the SI according to equation 2.

$$
\begin{aligned}
& \operatorname{CRT}(n)=S \times\left(\operatorname{MRT}_{l}(n-1)+0.5 \times \operatorname{MRT}_{l}(n)\right) \\
& +(1-S) \times\left(\operatorname{MRT}_{S}(n-1)+0.5 \times \operatorname{MRT}_{S}(n)\right)
\end{aligned}
$$

where CRT is the cumulative retention time of digesta in SI compartment $n$ in min and $S$ is the fraction of soluble starch breakdown products as part of the total amount of starch in digesta. MRT is the MRT of the solid (s) or liquid (1) fraction of digesta in min (calculations and results will be described elsewhere). For SI1, MRT $(n-1)$ is zero.

A modified version of the Chapman-Richards model was used to model in vitro digestion kinetics, as previously described by van Kempen et al. ${ }^{(19)}$ (equation 3).

Starch hydrolysis $=$ plateau $\times\left(1-\exp \left(-\frac{\frac{K}{100}}{\text { plateau }} \times 100 \times\right.\right.$ time $\left.)\right)$

where starch hydrolysis is expressed as percentage of starch in sample, plateau is the maximum amount of starch hydrolysed during digestion (as percentage of sample weight), which is calculated from the maximum glucose release $\times 0.9$, and $K$ is the rate of glucose release corrected for plateau effects (as percentage of starch hydrolysed to glucose per min). Time is the incubation time ( $\mathrm{min}$ ) since start of the in vitro procedure. The $K$ and plateau values of each starch sample were estimated by nonlinear regression procedures (PROC NLIN, SAS, version 9.4; SAS Institute). For estimation of the plateau value, a boundary was included forcing the estimation to be $\leq 1$. Amounts of in vitro RDS, SDS and RS were calculated based on the classification system of Englyst et al. ${ }^{(20)}$.

Effects of the experimental factors on DC and $\mathrm{DC}_{\mathrm{cr}}$ within each segment were tested using a general linear mixed model (PROC MIXED; SAS). Starch form (isolated starch, ground cereal, extruded cereal), starch source (barley, maize, HA maize), small-intestinal segment (SI1, SI2, SI3, SI4) and all interactions were included as fixed effects. Batch was included as random effect, and pig was considered as the experimental unit. Differences among starch forms within sources were considered pre-planned contrasts and were evaluated using contrast statements. Changes in DC throughout the SI within each starch source were analysed using a general linear mixed model, with segment as fixed effect. Segment within pig (subject) was modelled as R-side effect to account for repeated observations within pigs. Based on the fit statistics, a heterogeneous autoregressive covariance structure was assumed. The slice statement was used to identify effects of starch form, starch source and their interaction within each segment and to identify effects of segment within each starch form, starch source and sourceform combination. Contrast statements were used to compare segments within starch source. Data are presented as least square means and standard deviation of the mean unless stated otherwise. A retrospective power analysis was performed to validate the sample size of this study. Considering starch DC as the most important parameter, the power was evaluated using the variation in starch DC observed in this study, by calculating the critical $F$ value for a two-sided $\alpha$ level of 0.05 and for the mixed model study design ${ }^{(28)}$. A power greater than 0.95 was reached on the main effects of form, source and segment, the form $\times$ source interaction, and the source $\times$ segment interaction. For the form $\times$ segment interaction, a power of 0.44 was reached; and for the form $\times$ source $\times$ segment interaction, a power of 0.68 was reached. Significance was assumed at $P<0 \cdot 05$, while a tendency was considered when $0 \cdot 05<P \leq 0 \cdot 1$.

\section{Results}

\section{Effects of starch form, starch source and small-intestinal} segment on starch digestion coefficients

The sum of glucose and all-soluble $\alpha(1-4)$ maltodextrins was quantified as fraction of total unabsorbed starch residuals (online Supplementary Table S1) and used to calculate the DC of starch (Table 2). In addition to the linear $\alpha(1-4)$ maltodextrins, other (unidentified) starch-derived soluble 
Table 2. Digestion coefficients (DC) of starch in digesta recovered from four consecutive parts of the small intestine (SI) of pigs fed diets containing barley, maize or high-amylose maize starch, included as isolated powder, ground cereal or extruded cereal ${ }^{*} \dagger$

(Least square mean values and standard deviations)

\begin{tabular}{|c|c|c|c|c|c|c|c|c|c|c|c|c|c|c|c|}
\hline \multirow[b]{3}{*}{ DC } & \multicolumn{9}{|c|}{ Experimental diets $\ddagger$} & \multirow[b]{3}{*}{ SD } & & & & & \\
\hline & \multicolumn{3}{|c|}{ Barley } & \multicolumn{3}{|c|}{ Maize } & \multicolumn{3}{|c|}{ High-amylose maize } & & \multicolumn{3}{|c|}{$P \S$} & \multicolumn{2}{|c|}{ Effectll } \\
\hline & I & $\mathrm{G}$ & $E$ & 1 & $\mathrm{G}$ & $E$ & 1 & $\mathrm{G}$ & E & & Form & Source & $\begin{array}{l}\text { Form } \times \\
\text { source }\end{array}$ & Form & Source \\
\hline Max obs $\mathbb{I}$ & 10 & 10 & 9 & 10 & 10 & 9 & 7 & 7 & 10 & & & & & & \\
\hline Sl1 & 0.40 & 0.28 & 0.47 & $0.34^{\mathrm{c}, \mathrm{d}}$ & $0.19^{d}$ & $0.45^{\mathrm{c}}$ & $0.20^{f}$ & $0.16^{f}$ & $0.63^{\mathrm{e}}$ & 0.22 & $<0.0001$ & 0.592 & 0.0005 & $E>I=G$ & \\
\hline S12 & $0.68^{a}$ & $0.52^{\mathrm{b}}$ & $0.64^{a, b}$ & $0.57^{d}$ & $0.60^{\mathrm{d}}$ & $0.78^{\mathrm{c}}$ & $0.29^{f}$ & $0.35^{f}$ & $0.59^{\mathrm{e}}$ & 0.18 & 0.0009 & $<0.0001$ & $<0.0001$ & $E>I=G$ & $\mathrm{~B}=\mathrm{M}>\mathrm{A}$ \\
\hline SI3 & $0.96^{a}$ & $0.87^{\mathrm{b}}$ & $0.95^{\mathrm{a}}$ & $0.92^{c}$ & $0.82^{d}$ & $0.94^{\mathrm{C}}$ & $0.50^{\mathrm{g}}$ & $0.58^{f}$ & $0.71^{\mathrm{e}}$ & 0.06 & $<0.0001$ & $<0.0001$ & $<0.0001$ & $E>I>G$ & $B>M>A$ \\
\hline $\mathrm{SI} 4$ & 0.99 & 0.95 & 0.97 & $0.99^{c}$ & $0.84^{d}$ & $0.98^{\mathrm{c}}$ & $0.55^{f}$ & $0.60^{f}$ & $0.79^{\mathrm{e}}$ & 0.07 & $<0.0001$ & $<0.0001$ & $<0.0001$ & $E>I>G$ & $B>M>A$ \\
\hline$P^{\star *}$ & \multicolumn{3}{|c|}{$<0.0001$} & \multicolumn{3}{|c|}{$<0.0001$} & \multicolumn{3}{|c|}{$<0.0001$} & & & & & & \\
\hline Effectt† & \multicolumn{3}{|c|}{$\mathrm{SI} 1<\mathrm{SI} 2<\mathrm{SI} 3<\mathrm{SI} 4$} & \multicolumn{3}{|c|}{$\mathrm{SI} 1<\mathrm{SI} 2<\mathrm{SI} 3<\mathrm{SI} 4$} & \multicolumn{3}{|c|}{$\mathrm{SI} 1=\mathrm{SI} 2<\mathrm{SI} 3<\mathrm{SI} 4$} & & & & & & \\
\hline
\end{tabular}

a,b Differences among starch forms within all diets of barley origin $(P<0.05)$.

c,d Differences among starch forms within all diets of maize origin $(P<0.05)$.

e,f,g Differences among starch forms within all diets of high-amylose maize origin $(P<0.05)$.

* DC values are calculated using the dual-marker method ${ }^{(26)}$.

† SI4 is the terminal $1.5 \mathrm{~m}$ of the small intestine, whereas the rest of the small intestine is divided into three parts of equal length (SI1, SI2 and SI3, from proximal to distal SI, respectively).

‡ Starch forms and sources are abbreviated as follows: isolated (I), ground (G) and extruded (E) forms, originating from barley (B), maize (M), and high-amylose maize (A).

$\S$ Model established $P$ values for fixed effects of starch form (isolated, ground or extruded), source (barley, maize or high-amylose maize), and the interaction between form and source, within segment. When an interaction between form and source was identified, superscripts ${ }^{\mathrm{a}-\mathrm{g}}$ are used to indicate significant differences among starch forms within each starch source. Significance was assumed at $P<0.05$, while a tendency was considered when $0.05 P \leq 0.1$.

\| When a form or source effect is present $(P<0.05)$, ' $>$ ' indicates that the DC of a form/source is larger than others, whereas ' $=$ ' indicates that there is no difference in DC.

T The maximum number of replicate observations equals the amount of animals per treatment. In some segments, not enough digesta was present to allow chemical analysis,

causing one missing observation in SI1 of GB, SI1 of EA, SI4 of IB and SI4 of GM, and two missing observations in SI1 of EM.

** Model established $P$ values for fixed effects of segment, analysed per source.

†† When a segment effect is present $(P<0.05)$, ' $<$ ' indicates that the DC of a segment is smaller than others, whereas ' $=$ ' indicates that there is no difference in DC.

oligosaccharides were present, making up $<5 \%$ of the total peak area as measured with HPAEC, which were excluded in the calculation of starch DC. DC are also calculated according to the commonly used single-marker method $\left(\mathrm{DC}_{\mathrm{cr}}\right.$, online Supplementary Table S2).

In the absence of form $\times$ source $\times$ segment interactions $(P>0 \cdot 1)$, form $\times$ source interactions $(P<0 \cdot 01)$ are presented per segment. Due to the absence of segment $\times$ form interactions $(P>0 \cdot 1)$, segment effects on starch DC are presented within source. Overall, starch digestion increased with each following SI segment for all starch sources (0.04-0.32 DC units, $P<0.001)$, except for pigs fed HA maize, where SI1 and SI2 did not differ. For all segments, a significant interaction between starch form and source was present. The average DC of starch from maize origin was similar to that of barley in SI1 and SI2, but lower in SI3 and SI 4 (0.03 DC units in both segments, $P<0.05)$. The average starch DC of pigs fed HA maize was lower than that of pigs fed barley and maize from SI2 onwards (0.20-0.33 DC units, $P<0 \cdot 01)$. For barley-fed pigs, starch DC did not differ among starch forms in SI1 and SI4. In SI2, the DC of starch for pigs fed GB was lower ( 0.16 DC units, $P<0.05)$; and in SI3, the DC of starch for pigs fed GB was lower (0.08-0.09 DC units, $P<0.05)$ than for pigs fed IB and EB. In contrast, extrusion increased the DC of starch in all SI segments of maize-fed pigs $(0 \cdot 12-0.26$ DC units, $P<0 \cdot 05)$ and in all SI segments of pigs fed HA maize $(0 \cdot 13-0.47$ DC units, $P<0.05)$, compared with pigs fed ground cereals. The cereal matrix hampered starch digestion for maize fed pigs (IM $v$. GM) in SI3 and SI 4 (0.10-0.15 DC units, $P<0.0001$ ). For HA maize, the cereal matric (IA $v$. GA) hampered starch digestion in SI3 $(0.08$ DC units, $P<0.05)$ but not in SI4.
Glucose and maltodextrins released during starch digestion, as fraction of unabsorbed starch residuals

A typical HPAEC elution pattern of the soluble fraction of starch residuals in small-intestinal digesta (SI1-SI4) of pigs fed ground maize (online Supplementary Fig. S1) illustrates the presence of mainly glucose and linear $\alpha(1-4)$ maltodextrins. The fraction of unabsorbed starch residuals (1-DC) was divided into glucose, individual $\alpha(1-4)$ gluco-oligosaccharides (up to DP6), soluble gluco-polysaccharides (> DP6) and insoluble starch (Fig. 1). The sum of glucose and all soluble maltodextrins is referred to as soluble unabsorbed starch residuals. Expressed as a percentage of total unabsorbed starch residuals, these soluble residuals averaged $25 \%$ in SI 1 and $18 \%$ in SI 2 of barley-fed pigs, whereas this was only $4 \%$ in SI3 and $2 \%$ in SI4. For pigs fed maize-based diet, a similar pattern was observed as $17,13,4$ and $1 \%$ of total unabsorbed starch residuals were recovered as soluble starch residuals in SI1 to SI4, respectively. For HA maize-fed pigs, soluble starch residuals made up 10,11, 9 and $7 \%$ of the total unabsorbed starch residuals from SI1 to SI4, respectively. For all treatments, concentrations of glucose, maltose and maltotriose were numerically highest for all individually identified molecules. For barley-fed pigs, the sum of glucose, maltose and maltotriose averaged $32 \%$ of the soluble unabsorbed starch residuals across all SI segments, whereas this was $24 \%$ for maize-fed pigs and $12 \%$ for pigs fed HA maize. In the first SI segment of pigs fed extruded cereals, the sum of glucose, maltose and maltotriose constituted $33 \%$ of the soluble unabsorbed starch residuals, which was $21 \%$ for pigs fed isolated starch and $13 \%$ for pigs fed ground cereals. In SI2-4, 

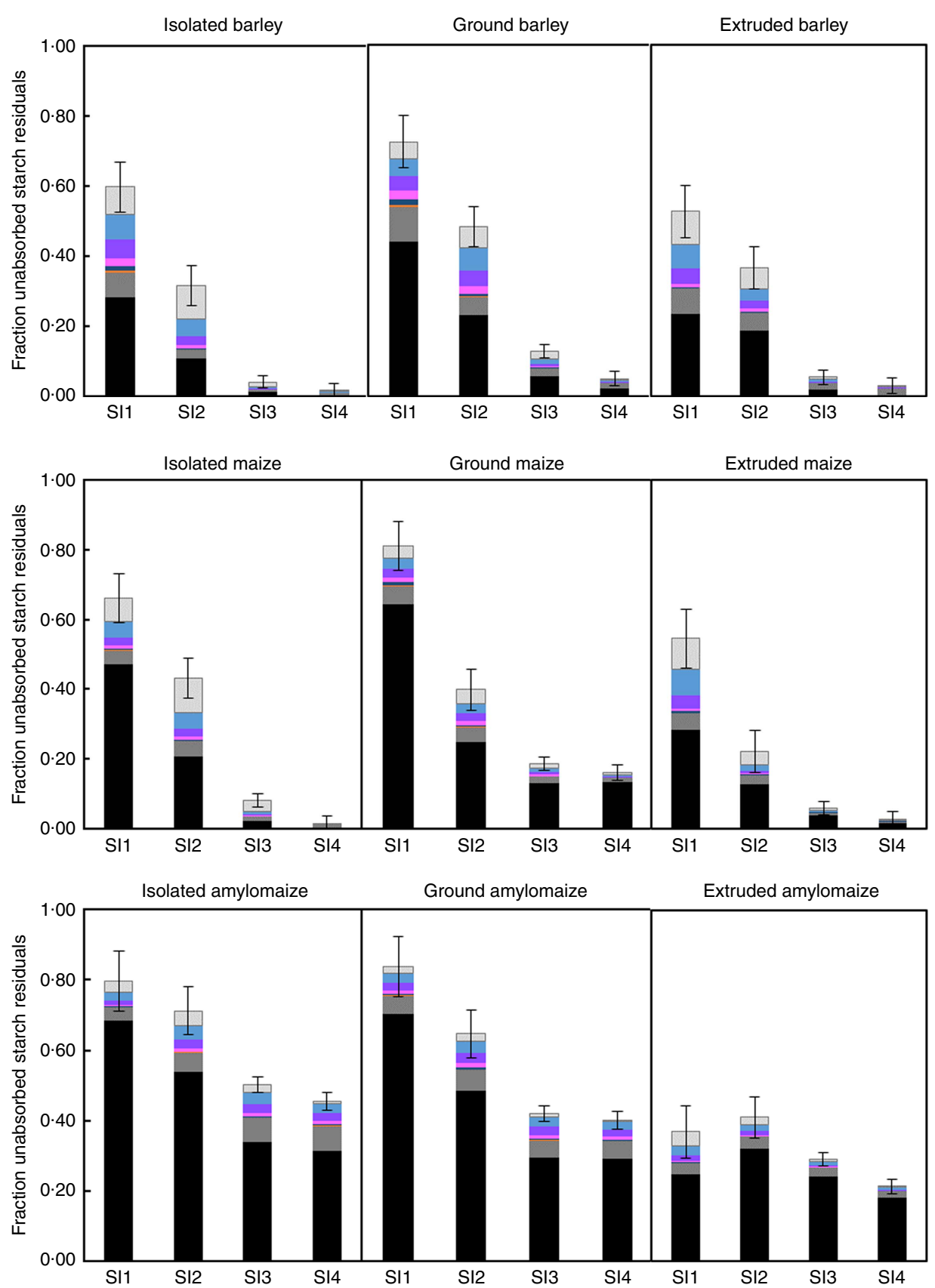

Fig. 1. Fraction unabsorbed starch residuals calculated as 1 - digestion coefficient (DC) in digesta recovered from four parts of the small intestine (SI) of pigs fed barley, maize or high-amylose maize-based diets which included starch as isolated powder, ground cereal or extruded cereal. Undigested starch is divided into soluble oligomers, quantified per individual oligomer up to degree of polymerisation (DP) 6 and insoluble starch. The error bars represent the standard error of the estimated mean DC. $\square$, DP1; $\square$, DP2; $\square$, DP3; $\square$, DP4; $\square$, DP5; $\square$, DP6; $\square,>$ DP6; $\square$, insoluble starch.

this concentration averaged $32 \%$ for pigs fed isolated starch, $19 \%$ for pigs fed ground cereals and $17 \%$ for pigs fed extruded cereals.

\section{Visual inspection of undigested starch}

Before ingestion, starch consisted largely of undamaged starch granules, both at individual granule level (Fig. 2, $5000 \times$ magnified) and within the ground cereal matrix (Fig. 3, 1000× magnified). Furthermore, starch in all ground cereals was mainly present inside a protein and cell wall matrix, which was damaged upon extrusion (Fig. 3). Individual starch granules of diets containing isolated starch showed signs of digestion in all parts of the SI, although digestion appeared more extensive for barley and maize starch granules compared with HA maize starch (Fig. 2). Digestion of starch fed as ground cereals was hampered by the protein and cell wall matrix, which remained intact for a part throughout the SI (Fig. 4 and online Supplementary Fig. S2). 


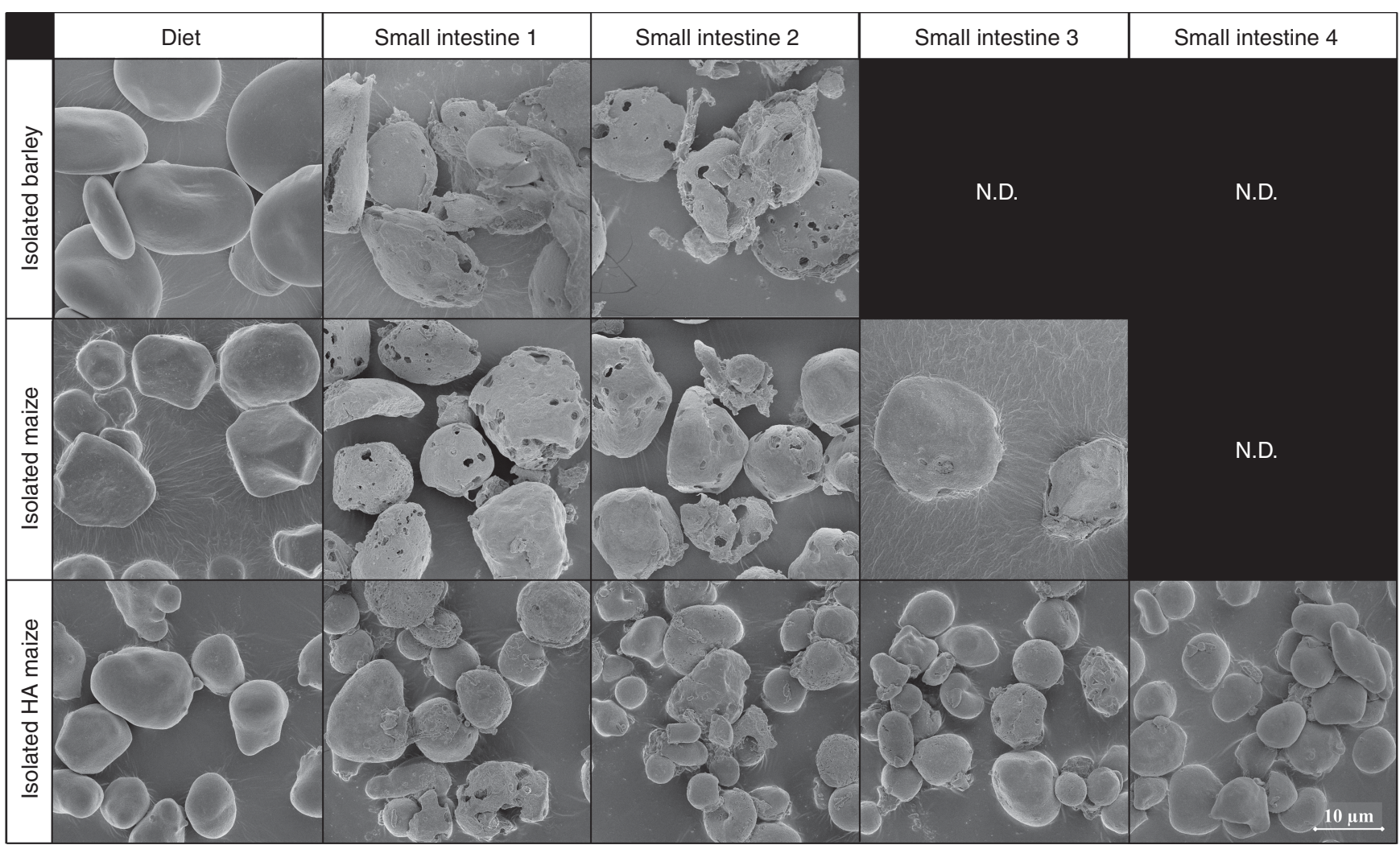

Fig. 2. Typical scanning electron microscope (SEM) images of starch granules in digesta of pigs fed diets containing isolated starch from barley, maize or highamylose (HA) maize origin, in diets and four segments of the small intestine, 5000x magnified. N.D. is used to indicate that not enough insoluble starch residues were present in those small intestine compartments to enable SEM analysis (i.e. not determined).

\section{In vitro starch digestion kinetics}

For all starch sources, the rate of in vitro starch digestion was measured and found to be higher for extruded diets compared with diets containing isolated starch and ground cereals (Table 3). Furthermore, each HA maize starch was digested slower in vitro than barley and maize starch of the same form. Extrusion resulted in a substantial increase in RDS, which was around $20 \%$ higher in barley and maize starch compared with HA maize starch. Consequently, extruded cereals contained low amounts of SDS and little (HA maize) or no RS (barley and maize). Ground barley and maize were digested slower than isolated barley and maize starch, resulting in higher levels of RDS for IB $v$. GB and IM $v$. GM. In contrast, isolated HA maize starch and ground HA maize were digested at a similar rate, resulting in similar levels of RDS, which were much lower than RDS levels of IB, IM, GB and GM. Consequently, IA and GA contained considerable higher levels of RS, but not SDS, than all other diets.

\section{Discussion}

The aim of this study was to assess the effects of variation in botanic starch source and processing form on the kinetics of starch disappearance along the GIT of pigs and to relate this to the in vitro predicted digestion kinetics. In addition, the structure of starch residuals that remained unabsorbed in the small intestine was analysed to obtain more information on the digestive mechanisms of starch hydrolysing enzymes.

\section{Influence of intrinsic starch properties v. the cereal matrix}

An in-depth analysis of the intrinsic properties of maize, barley and HA maize starch and their relation to in vitro digestion kinetics is presented elsewhere ${ }^{(11)}$. Briefly, maize and barley starch used in this study have comparable intrinsic properties, whereas HA maize has a higher amylose content (55\%) compared with barley and maize starch (20\%). Furthermore, HA maize starch has a different type and amount of crystalline structure, less pores and a different amylopectin structure. These intrinsic properties of HA maize hampered ileal digestibility illustrated by the lower ileal starch digestibility of IA (66\%) compared with IM (99\%), which confirms the results of in vivo studies ${ }^{(29-31)}$.

Presence of the cereal matrix hampered ileal starch digestion for maize but not for barley and HA maize. This is illustrated by a reduced ileal starch DC for pigs fed ground $v$. isolated and maize, whereas this difference is absent for barley and HA maize. Results of in vivo studies with pigs have indicated that a reduction in the particle size, thus an increased damage of protein matrix and cell walls, increased ileal starch digestibility of both barley, from 0.92 to 0.96 units $^{(18)}$, and maize, from 0.89 to 0.97 units $^{(32)}$. In addition, a reduction in the particle size of maize increased starch DC in the duodenum and jejunum of pigs $^{(33)}$. 

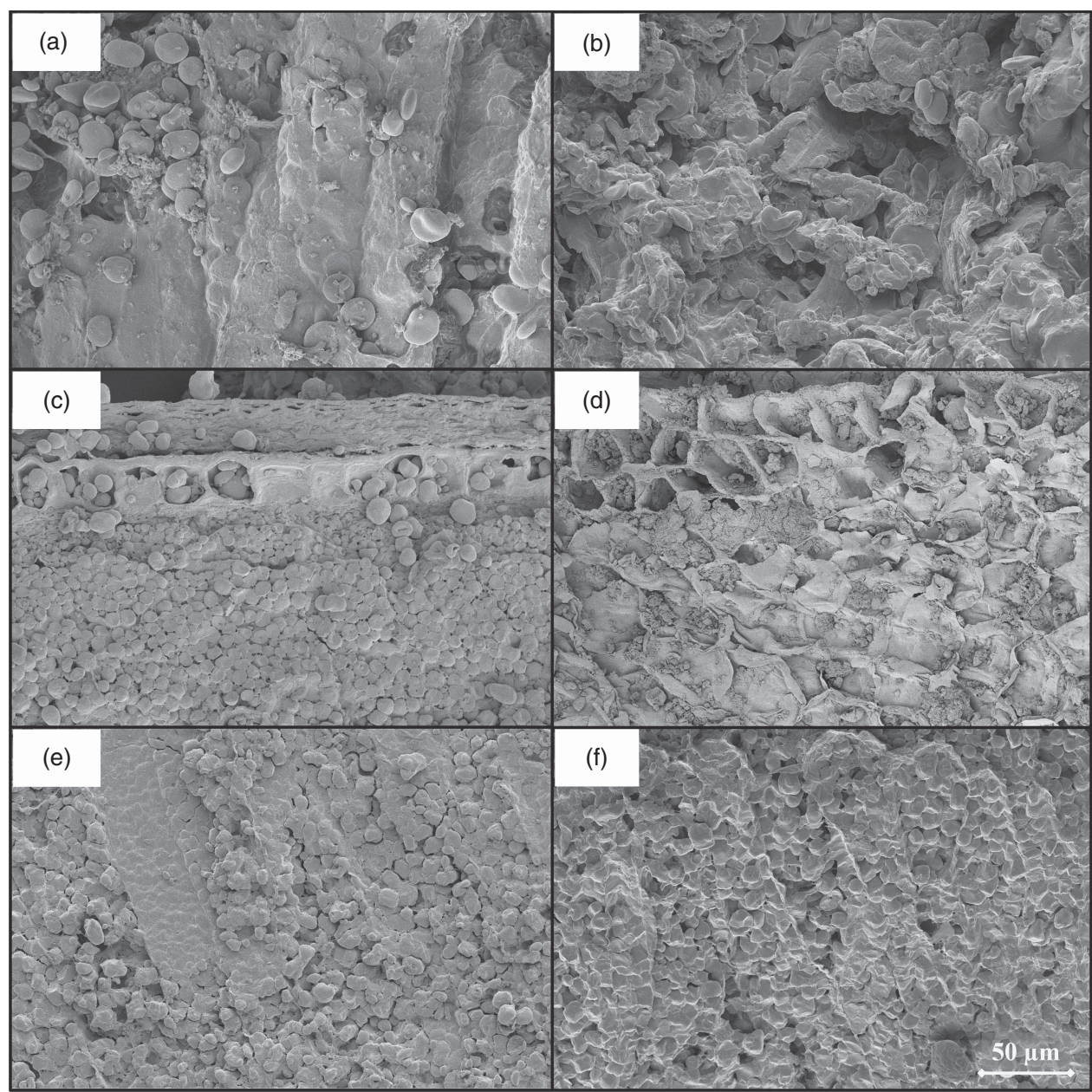

Fig. 3. Scanning electron microscope images of diets containing barley in ground (a) and extruded forms (b), maize in ground (c) and extruded forms (d), and highamylose maize in ground (e) and extruded forms (f), 1000x magnified.

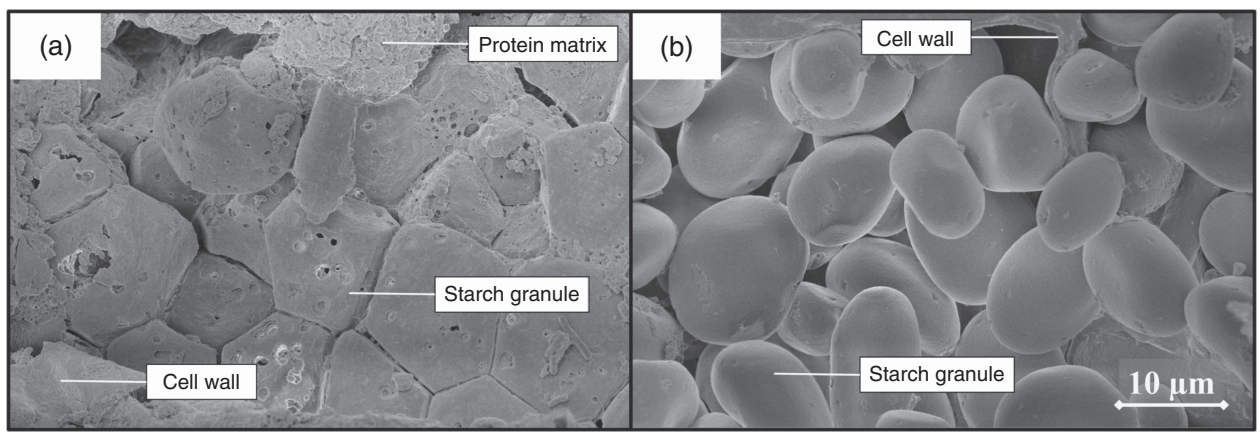

Fig. 4. Scanning electron microscope image of digesta recovered from small intestine 4 of a pig fed ground maize (a) and of a pig fed ground barley (b), 5000x magnified.

In this research, neither cereal endosperm nor cell wall structures were examined. Analysis with SEM revealed undigested protein residues covering starch granules in the distal SI parts of pigs fed ground maize (Fig. 4). This indicates the presence of substantial fractions of hard endosperm, which is typically richer in indigestible proteins ${ }^{(14)}$. In contrast, only loosely packed starch granules were identified for barley (Fig. 4 ), suggesting the presence of mainly soft endosperm that allows for a more rapid starch digestion ${ }^{(34)}$. SEM analysis also revealed large fractions of starch granules entrapped within intact cell wall material in SI4 of maize-fed pigs (online Supplementary Fig. S2), which was not observed for barley-fed pigs. Based on previous research, it is suggested that this is caused by larger fractions of soluble fibres, which are generally more abundant in barley than in maize, and more easily degraded by monogastrics ${ }^{(15,35)}$.

In summary, both the endosperm cell wall and protein structure seem to contribute to a higher RS fraction in ground 
maize compared with ground barley. In ground HA maize, the cereal matrix likely has a similar effect as seen in ground maize, as substantial fractions of hard endosperm were observed in HA maize. However, intrinsic properties of HA maize seem to hamper digestion more than its cereal matrix, because the DC of isolated HA maize did not exceed the DC of ground HA maize in any of the SI parts.

\section{Effect of extrusion on in vivo starch digestion}

Extrusion increased the ileal digestibility of maize and HA maize starch with 0.15 and 0.19 units to 0.98 and 0.79 units, respectively. This is more than expected based on previous research with maize-fed pigs, where a modest increase in ileal digestibility of 0.02 units was identified ${ }^{(17)}$. However, the starch DC measured for native ground maize used in the current study (0.86) was lower than in the previous study $(0 \cdot 98)^{(17)}$. Ileal starch digestibility of ground barley was nearly complete in our study, leaving no room for an increase by extrusion, which was observed in previous work ${ }^{(36)}$. For HA maize, starch DC in the proximal SI was increased by extrusion, whereas the DC remained almost similar to that of SI1 in subsequent SI segments. As visualised by SEM, the effect of extrusion on HA maize appeared smaller than observed for maize and barley (Fig. 3). Indeed, the molecular properties of HA starch led to a higher gelatinisation temperature of starch, causing similar processing conditions to result in a lower degree of gelatinisation ${ }^{(37-39)}$.

\section{Mechanisms of starch hydrolysing enzymes in the small intestine}

A substantial part of the unabsorbed starch residuals in the small intestine was present as soluble oligomers (Fig. 1), especially for pigs fed barley and maize (on average 63 and $42 \%$ across starch forms, respectively). Our novel findings indicate that the soluble oligomer fraction in SI1 and SI2 consisted mostly of molecules with DP $\leq 3$. Maltose and maltotriose are typical end products of pancreatic $\alpha$-amylase ${ }^{(40)}$, whereas glucose is the end product of brush-border enzyme activity ${ }^{(41)}$. The presence of glucose in the proximal SI suggests a delay in the absorption of glucose that is produced by brush-border enzymes, which was observed before for pigs fed native maize starch ${ }^{(42)}$. In addition, the high concentration of glucose in digesta indicates activity of brush-border enzymes, which are not bound to the gut wall. This corresponds well with the results of recent experiments, which indicated that a proportion of brush-border enzymes is actively budded off as brush-border membrane vesicle $e^{(43)}$ and that the enzymes might transit and diffuse to all parts of the intestinal lumen ${ }^{(44)}$. The presence of maltose and maltotriose reveals that the rate of starch hydrolysis by $\alpha$-amylase exceeds the rate of maltose and maltotriose degradation by brush-border enzymes.

In digesta of pigs fed isolated barley or maize starch, granular starch residues in SI1 and SI2 showed severe signs of digestion (Fig. 2), whereas little to no granular residues were left in SI3 and SI4. Digesta of pigs fed IA contained granular starch residuals in all SI compartments. Granules remaining in SI4 showed barely signs of digestion, indicating that granules are either fully digested 
or left untouched. This heterogeneous digestion of HA starch has been observed previously in vitro, where indeed most residual granules from HA maize starch were largely intact ${ }^{(45,46)}$.

\section{Comparing in vivo starch digestion kinetics with an in vitro assay}

The rate of in vitro starch digestion measured in this study was higher for extruded cereals compared with ground cereals and isolated starch. In addition, the rate of in vitro starch digestion of ground cereals was lower than that of isolated starch. This confirms the results of previous in vitro studies, which showed that the presence of a cereal matrix slows starch digestion ${ }^{(34,47)}$ and that extrusion increases starch digestion rates ${ }^{(36)}$. In addition, every form of HA maize starch analysed in this study was digested slower than maize starch of the same form. This is also in agreement with in vitro results, demonstrating a negative correlation between digestion rates and an increased amylose content, B-type of crystalline structure and long amylopectin side chains ${ }^{(19,30,48,49)}$.

In vitro and in vivo hydrolysis rates were visually compared (Fig. 5), by plotting in vivo starch hydrolysis in all segments of pigs on a single treatment, against the cumulative intestinal retention time (online Supplementary Table S3). For this plot, maltodextrins with DP $\leq 3$ were assumed to be end products of $\alpha$-amylase hydrolysis ${ }^{(40)}$. In the same figure, in vitro starch hydrolysis was plotted against the incubation time. For extruded starch, the initial rate of starch digestion, in SI1 and SI2, compares well between in vitro and in vivo data. For isolated and ground starch sources, however, the in vitro assay underestimates the initial rate of starch digestion. The extent of in vivo starch digestion in SI 1 measured in this study (on average 35\% for all diets) is close to that in the duodenal and initial jejunum of growing pigs fed ground maize (on average $45 \%)^{(33)}$. In addition, it corresponds well with the extend of starch digested in the first third of the SI of growing pigs fed ground oats (on average $57 \%)^{(50)}$. The difference between in vitro and in vivo starch digestion becomes smaller towards the distal SI for barley and maize starch in isolated or ground form, whether it remains rather constant for IA and GA.

The similarity between our in vivo data and results of previous studies ${ }^{(33,50)}$, emphasises that the in vitro method systematically underestimates the initial in vivo rate of starch digestion. This contributes to the ongoing debate on the predictability of in vivo data by in vitro assays ${ }^{(51,52)}$. Amongst others, the absence of brush-border enzymes in the in vitro assay may result in an underestimation of in vivo starch digestion $^{(53,54)}$. Alternatively, digestion processes initiated in the stomach may partly explain the rapid initial starch hydrolysis in vivo. This includes the possibility of starch hydrolysis in the stomach but also alterations of the digesta matrix inadequately simulated in vitro. Finally, errors in the measurement of in vivo digesta passage kinetics may contribute to differences between in vivo and in vitro results.
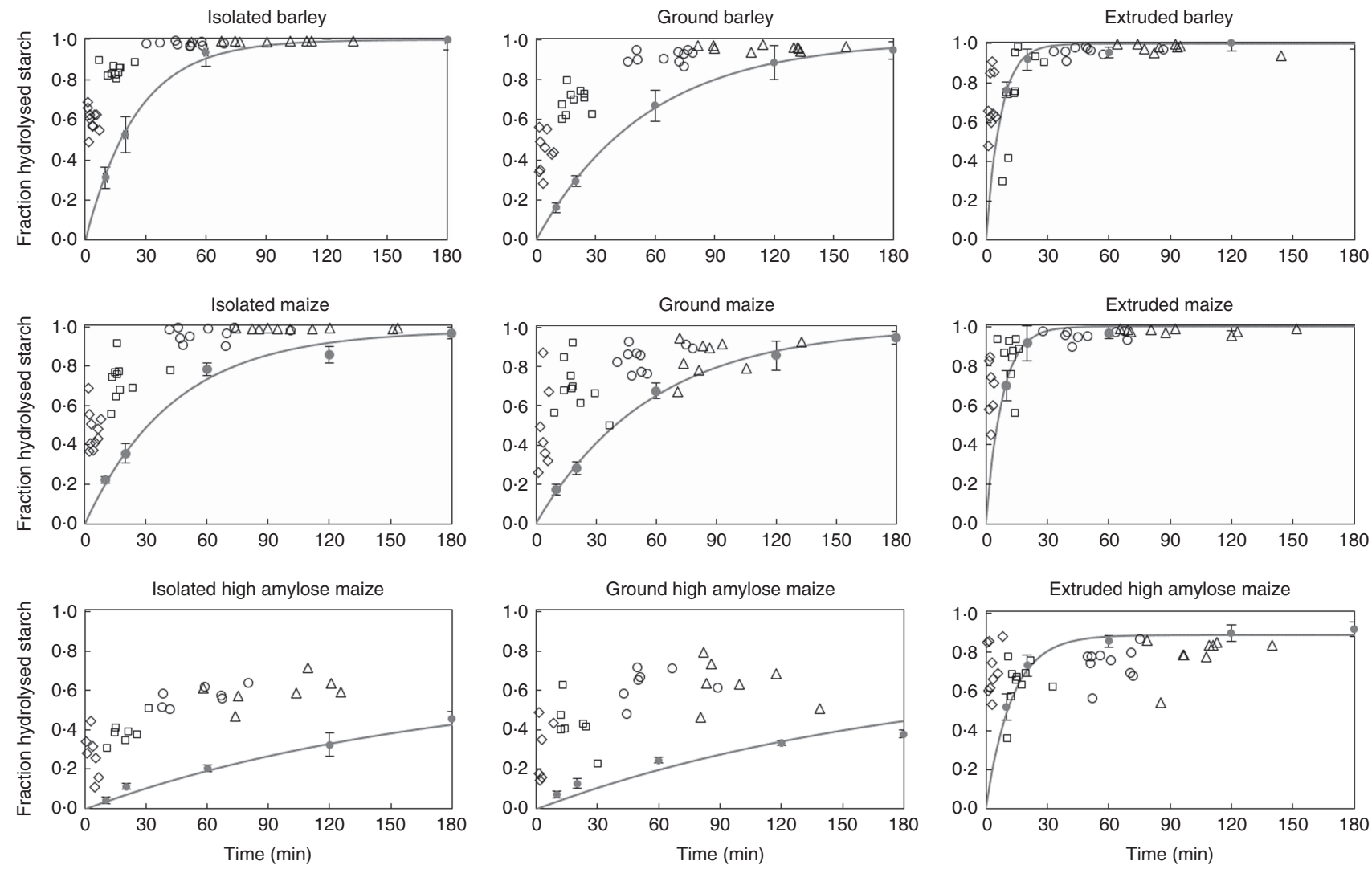

Fig. 5. Digestion coefficients of starch measured in digesta recovered from part $1(\diamond), 2(\square), 3(\circ)$ and $4(\Delta)$ of the small intestine of individual pigs fed barley, maize or high-amylose maize based diets which included starch as isolated powder, ground cereal or extruded cereal, plotted against the cumulative retention time. In each graph, in vitro starch hydrolysis is plotted against incubation time. Symbols ( $)$ indicate the average of in triplicate measured values; lines represent the first-order kinetic model fitted to the data points. Error bars represent the standard deviation of in vitro measured starch digestion. 
All starch that is digested in vitro in $120 \mathrm{~min}$, but not in 20 min, can be considered SDS according to Englyst' classification $^{(20)}$. This fraction corresponds to a gradual and prolonged glucose release in vivo, leading to an extended glycaemic index ${ }^{(55)}$. Barley and maize diets, containing starch in isolated or ground form, were high in SDS according to in vitro digestion but did not release a relevant amount of glucose in the distal part of the SI. IA and GA contained $33 \%$ in vitro digestible starch, of which $20 \%$ was characterised as RDS and $80 \%$ as SDS. In contrast, IA and GA were in vivo digested for 65 and $68 \%$, respectively, of which half disappeared from the SI within the first $10 \mathrm{~min}$. The fraction of intact starch barely differed between SI3 and SI4 (Fig. 1), which indicates that starch escaping initial hydrolysis in vitro does not necessarily lead to an increase in starch hydrolysis in more distal parts of the SI. Consequently, the in vivo glucose release, and thus glucose absorption, is less gradual than expected based on in vitro analysis.

\section{Conclusions}

Starch digestion for barley and maize is primarily determined by the cereal matrix, whereas digestion of HA maize is limited by intrinsic starch properties. The presence of soluble maltodextrins in SI digesta illustrates that a combination of $\alpha$-amylase and brush-border enzymes determine the rate of in vivo starch digestion, but that variation in starch digestion kinetics, caused by the feed matrix, is not adequately predicted by current in vitro methods. The underestimation of initial starch digestion in vitro indicates that the role of the stomach on starch digestion is currently underestimated. The present results indicate that glucose release from SDS is less gradual than predicted from in vitro analysis.

\section{Acknowledgements}

The authors would like to thank Ruud Dekker, Pieter Roskam, Tiny Franssen-Verheijen, Tamme Zandstra, Marit Noorloos (Wageningen University and Research, Wageningen, the Netherlands), Jos van Hees, and animal caretakers at the Laverdonk Research Farm (Agrifirm North West Europe, Heeswijk-Dinther, the Netherlands) for their advice and/or skilled assistance during the set-up and practical work of this study.

This project is jointly financed by the Topsector Agri\&Food and Agrifirm as coordinated by the Dutch Carbohydrate Competence Center (CCC-ABC; www.cccresearch.nl).

B. M. J. M., H. A. S., E. M. A. M. B. and W. J. J. G. designed the experiment. B. M. J. M. and T. F. conducted research. B. M. J. M., S. d. V. and W. J. J. G. performed statistical analysis. B. M. J. M. wrote the manuscript. S. d. V., H. A. S., E. M. A. M. B. and W. J. J. G. revised the manuscript. All authors have read and approved the final manuscript.

All authors declare that they have no conflicts of interest.

\section{Supplementary material}

For supplementary material/s referred to in this article, please visit https://doi.org/10.1017/S0007114519000503

\section{References}

1. Regmi PR, van Kempen TA, Matte JJ, et al. (2011) Starch with high amylose and low in vitro digestibility increases short-chain fatty acid absorption, reduces peak insulin secretion, and modulates incretin secretion in pigs. J Nutr 141, 398-405.

2. Da Silva CS, Bosch G, Bolhuis J, et al. (2014) Effects of alginate and resistant starch on feeding patterns, behaviour and performance in ad libitum-fed growing pigs. Animal 8, 1917-1927.

3. Bolhuis J, van den Brand H, Staals S, et al. (2008) Effects of fermentable starch and straw-enriched housing on energy partitioning of growing pigs. Animal 2, 1028-1036.

4. van den Borne JJGC, Schrama JW, Heetkamp MJW, et al. (2007) Synchronising the availability of amino acids and glucose increases protein retention in pigs. Animal 1, 666-674.

5. Weurding R, Enting H \& Verstegen M (2003) The relation between starch digestion rate and amino acid level for broiler chickens. Poult Sci 82, 279-284.

6. de Vries S, Gerrits WJ, Kabel MA, et al. (2016) $\beta$-Glucans and resistant starch alter the fermentation of recalcitrant fibers in growing pigs. PLOS ONE 11, e0167624.

7. Tester RF, Karkalas J \& Qi X (2004) Starch—composition, fine structure and architecture. J Cereal Sci 39, 151-165.

8. Jane J, Chen Y, Lee L, et al. (1999) Effects of amylopectin branch chain length and amylose content on the gelatinization and pasting properties of starch. Cereal Chem 76, 629-637.

9. Fannon JE, Hauber RJ \& BeMiller JN (1992) Surface pores of starch granules. Cereal Chem 69, 284-288.

10. Jiang H, Jane JL, Acevedo D, et al. (2010) Variations in starch physicochemical properties from a generation-means analysis study using amylomaize V and VII parents. J Agric Food Chem 58, 5633-5639.

11. Martens BMJ, Gerrits WJ, Bruininx EMAM, et al. (2018) Amylopectin structure and crystallinity explains variation in digestion kinetics of starches across botanic sources in an in vitro pig model. J Anim Sci Biotechnol 9, 91-103.

12. Giuberti G, Gallo A \& Masoero F (2012) Plasma glucose response and glycemic indices in pigs fed diets differing in in vitro hydrolysis indices. Animal 6, 1068-1076.

13. Chandra GS, Proudlove MO \& Baxter ED (1999) The structure of barley endosperm - an important determinant of malt modification. J Sci Food Agric 79, 37-46.

14. Dombrink-Kurtzman M \& Bietz J (1993) Zein composition in hard and soft endosperm of maize. Cereal Chem 70, 105-108.

15. Knudsen KB (2001) The nutritional significance of "dietary fibre" analysis. Anim Feed Sci Technol 90, 3-20.

16. Abdollahi M, Ravindran V, Wester T, et al. (2010) Influence of conditioning temperature on performance, apparent metabolisable energy, ileal digestibility of starch and nitrogen and the quality of pellets, in broiler starters fed maize-and sorghumbased diets. Anim Feed Sci Technol 162, 106-115.

17. Rojas O, Vinyeta E \& Stein H (2016) Effects of pelleting, extrusion, or extrusion and pelleting on energy and nutrient digestibility in diets containing different levels of fiber and fed to growing pigs. J Anim Sci 94, 1951-1960.

18. Knudsen KEB, Steenfeldt S, Hedemann MS, et al. (2006) In vivo methods to study the digestion of starch in pigs and poultry. Anim Feed Sci Technol 130, 114-135.

19. van Kempen TA, Regmi PR, Matte JJ, et al. (2010) In vitro starch digestion kinetics, corrected for estimated gastric emptying, predict portal glucose appearance in pigs. J Nutr 140, 1227-1233.

20. Englyst HN, Kingman SM \& Cummings JH (1992) Classification and measurement of nutritionally important starch fractions. Eur J Clin Nutr 46, S33-S50.

21. Blok M \& Spek J (2016) CVB Veevoedertabel 2016: chemische samenstellingen en nutritionele waarden van voedermiddelen: 
CVB Programma (CVB Feed Table 2016: Chemical Composition and Nutritional Value of Feedstuffs: CVB programme).

22. de Vries S, Pustjens AM, Kabel MA, et al. (2013) Processing technologies and cell wall degrading enzymes to improve nutritional value of dried distillers grain with solubles for animal feed: an in vitro digestion study. J Agric Food Chem 61, 8821-8828.

23. International Organisation for Standardization (2018) ISO methods. http://www.iso.org (accessed July 2018).

24. van Bussel W, Kerkhof F, van Kessel T, et al. (2010) Accurate determination of titanium as titanium dioxide for limited sample size digestibility studies of feed and food matrices by inductively coupled plasma optical emission spectrometry with real-time simultaneous internal standardization. At Spectrosc 31, 81-88.

25. Williams C, David DJ \& Iismaa O (1962) The determination of chromic oxide in faeces samples by atomic absorption spectrophotometry. J Agric Sci 59, 381-385.

26. Vries Sd \& Gerrits WJJ (2018) The use of tracers or markers in digestion studies. In Feed Evaluation Science,pp. 275-294 [PJ Moughan and WH Hendriks, editors]. Wageningen: Wageningen Academic Publishers

27. Kotb A \& Luckey T (1972) Markers in nutrition. Nutr Abstr Rev 42, 813-845.

28. Stroup WW (1999) Mixed model procedures to assess power, precision, and sample size. In The Design of Experiments 1999 Proceedings of the Biopharmaceutical Section, pp. 15-24. Alexandria, VA: American Statistical Association.

29. Bird AR, Vuaran M, Brown I, et al. (2007) Two high-amylose maize starches with different amounts of resistant starch vary in their effects on fermentation, tissue and digesta mass accretion, and bacterial populations in the large bowel of pigs. Br J Nutr 97, 134-144.

30. Li Y, Zhang AR, Luo HF, et al. (2015) In vitro and in vivo digestibility of corn starch for weaned pigs: effects of amylose: amylopectin ratio, extrusion, storage duration, and enzyme supplementation. J Anim Sci $93,3512-3520$

31. Fouhse JM, Gänzle MG, Regmi PR, et al. (2015) High amylose starch with low in vitro digestibility stimulates hindgut fermentation and has a bifidogenic effect in weaned pigs. $J$ Nutr 145, 2464-2470

32. Rojas O \& Stein H (2015) Effects of reducing the particle size of corn grain on the concentration of digestible and metabolizable energy and on the digestibility of energy and nutrients in corn grain fed to growing pigs. Livest Sci 181, 187-193.

33. Amaral N, Amaral L, Cantarelli V, et al. (2015) Influence of maize particle size on the kinetics of starch digestion in the small intestine of growing pigs. Anim Prod Sci 55, 1250-1254.

34. Dhital S, Warren FJ, Butterworth PJ, et al. (2017) Mechanisms of starch digestion by $\alpha$-amylase - structural basis for kinetic properties. Crit Rev Food Sci Nutr 57, 875-892.

35. de Vries S, Pustjens AM, Schols HA, et al. (2012) Improving digestive utilization of fiber-rich feedstuffs in pigs and poultry by processing and enzyme technologies: a review. Anim Feed Sci Technol 178, 123-138.

36. Sun T, Laerke HN, Jorgensen H, et al. (2006) The effect of extrusion cooking of different starch sources on the in vitro and in vivo digestibility in growing pigs. Anim Feed Sci Technol 131, 66-85.

37. Li M, Hasjim J, Xie F, et al. (2014) Shear degradation of molecular, crystalline, and granular structures of starch during extrusion. Starch/Stärke 66, 595-605.
38. Liu W-C, Halley PJ \& Gilbert RG (2010) Mechanism of degradation of starch, a highly branched polymer, during extrusion. Macromolecules 43, 2855-2864.

39. Waigh TA, Gidley MJ, Komanshek BU, et al. (2000) The phase transformations in starch during gelatinisation: a liquid crystalline approach. Carbobydr Res 328, 165-176.

40. Robyt JF \& French D (1970) The action pattern of porcine pancreatic $\alpha$-amylase in relationship to the substrate binding site of the enzyme. I Biol Chem 245, 3917-3927.

41. Hooton D, Lentle R, Monro J, et al. (2015) The secretion and action of brush border enzymes in the mammalian small intestine. Rev Physiol Biochem Pharmacol 168, 59-118.

42. Noah L, Lecannu G, David A, et al. (1999) Digestion of starch and glycaemic response to mixed meals in pigs. Reprod Nutr Dev 39, 245-254.

43. McConnell RE \& Tyska MJ (2007) Myosin-1a powers the sliding of apical membrane along microvillar actin bundles. J Cell Biol 177, 671-681.

44. McConnell RE, Higginbotham JN, Shifrin DA, et al. (2009) The enterocyte microvillus is a vesicle-generating organelle. J Cell Biol 185, 1285-1298.

45. Evans A \& Thompson DB (2004) Resistance to $\alpha$-amylase digestion in four native high-amylose maize starches. Cereal Chem 81, 31-37.

46. Brewer LR, Cai L \& Shi Y-C (2012) Mechanism and enzymatic contribution to in vitro test method of digestion for maize starches differing in amylose content. J Agric Food Chem 60, 4379-4387.

47. Al-Rabadi GJS, Gilbert RG \& Gidley MJ (2009) Effect of particle size on kinetics of starch digestion in milled barley and sorghum grains by porcine alpha-amylase. J Cereal Sci 50, 198-204.

48. Asare EK, Jaiswal S, Maley J, et al. (2011) Barley grain constituents, starch composition, and structure affect starch in vitro enzymatic hydrolysis. I Agric Food Chem 59, 4743-4754

49. Shrestha AK, Blazek J, Flanagan BM, et al. (2012) Molecular, mesoscopic and microscopic structure evolution during amylase digestion of maize starch granules. Carbohydr Polym 90, 23-33.

50. Knudsen KEB, Jensen BB \& Hansen I (1993) Digestion of polysaccharides and other major components in the small and large intestine of pigs fed on diets consisting of oat fractions rich in $\beta$-D-glucan. Br J Nutr 70, 537-556.

51. Hasjim J, Lavau GC, Gidley MJ, et al. (2010) In vivo and in vitro starch digestion: are current in vitro techniques adequate? Biomacromolecules 11, 3600-3608.

52. Bohn T, Carriere F, Day L, et al. (2018) Correlation between in vitro and in vivo data on food digestion. What can we predict with static in vitro digestion models? Crit Rev Food Sci Nutr 58, 2239-2261.

53. Dhital S, Lin AH-M, Hamaker BR, et al. (2013) Mammalian mucosal $\alpha$-glucosidases coordinate with $\alpha$-amylase in the initial starch hydrolysis stage to have a role in starch digestion beyond glucogenesis. PLOS ONE 8, e62546.

54. Ao Z, Quezada-Calvillo R, Sim L, et al. (2007) Evidence of native starch degradation with human small intestinal maltase-glucoamylase (recombinant). FEBS Lett $\mathbf{5 8 1}$, $2381-2388$.

55. Zhang G \& Hamaker BR (2009) Slowly digestible starch: concept, mechanism, and proposed extended glycemic index. Crit Rev Food Sci Nutr 49, 852-867. 